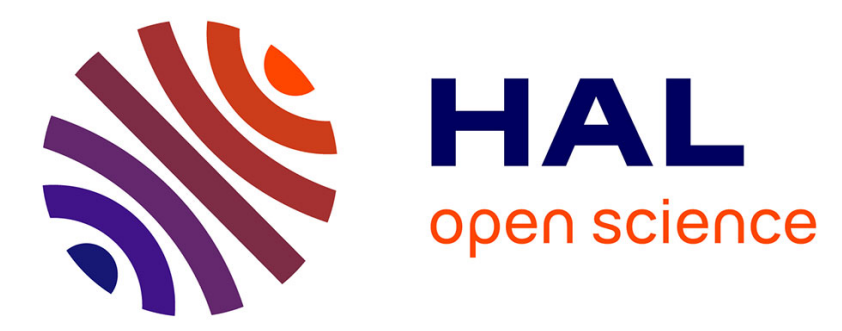

\title{
Optical levitation using single mode fibers and its application to self-centering of microlenses
}

Jean-Paul Pocholle, Jean Raffy, Yves Combemale, Michel Papuchon, Gérald Roosen, Marie-Thérèse Plantegenest

\section{- To cite this version:}

Jean-Paul Pocholle, Jean Raffy, Yves Combemale, Michel Papuchon, Gérald Roosen, et al.. Optical levitation using single mode fibers and its application to self-centering of microlenses. Applied Physics Letters, 1984, 45 (4), pp.350-352. hal-00867010

\section{HAL Id: hal-00867010 https://hal-iogs.archives-ouvertes.fr/hal-00867010}

Submitted on 23 May 2016

HAL is a multi-disciplinary open access archive for the deposit and dissemination of scientific research documents, whether they are published or not. The documents may come from teaching and research institutions in France or abroad, or from public or private research centers.
L'archive ouverte pluridisciplinaire HAL, est destinée au dépôt et à la diffusion de documents scientifiques de niveau recherche, publiés ou non, émanant des établissements d'enseignement et de recherche français ou étrangers, des laboratoires publics ou privés. 


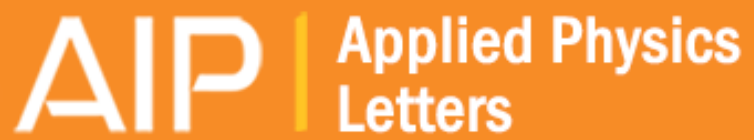

\section{Optical levitation using single mode fibers and its application to self-centering of microlenses}

Jean-Paul Pocholle, Jean Raffy, Yves Combemale, Michel Papuchon, G. Roosen, and M. T. Plantegenest

Citation: Applied Physics Letters 45, 350 (1984); doi: 10.1063/1.95266

View online: http://dx.doi.org/10.1063/1.95266

View Table of Contents: http://scitation.aip.org/content/aip/journal/apl/45/4?ver=pdfcov

Published by the AIP Publishing

Articles you may be interested in

Formation and conversion of defect centers in low water peak single mode optical fiber induced by gamma rays irradiation

J. Appl. Phys. 107, 044904 (2010); 10.1063/1.3273363

Efficient optical pulse compression using chalcogenide single-mode fibers

Appl. Phys. Lett. 88, 081116 (2006); 10.1063/1.2178772

Fluid self-centering vibration and shock mount

J. Acoust. Soc. Am. 68, 1016 (1980); 10.1121/1.384878

The Self-Centered Shadow

Am. J. Phys. 21, 578 (1953); 10.1119/1.1933562

Self-Centered Shadow

Am. J. Phys. 21, 234 (1953); 10.1119/1.1933405

\section{MULTIPHYSICS SIMULATION}

\section{Modeling and App Design Stories}
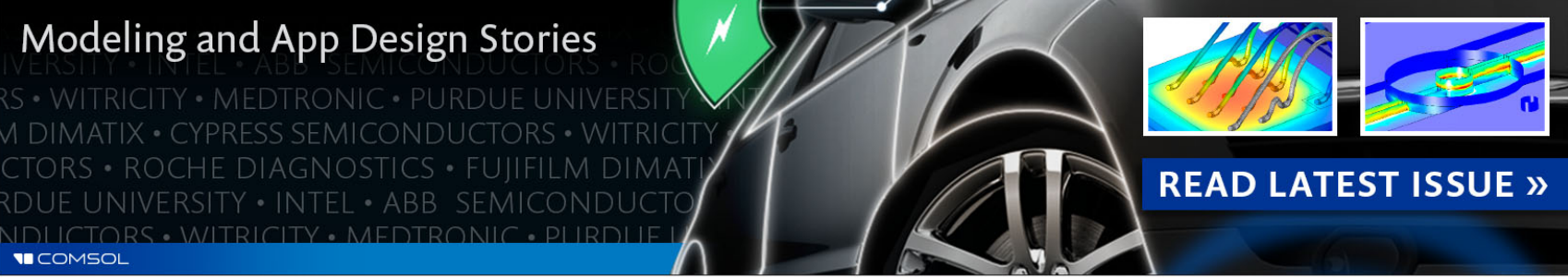

READ LATEST ISSUE » 


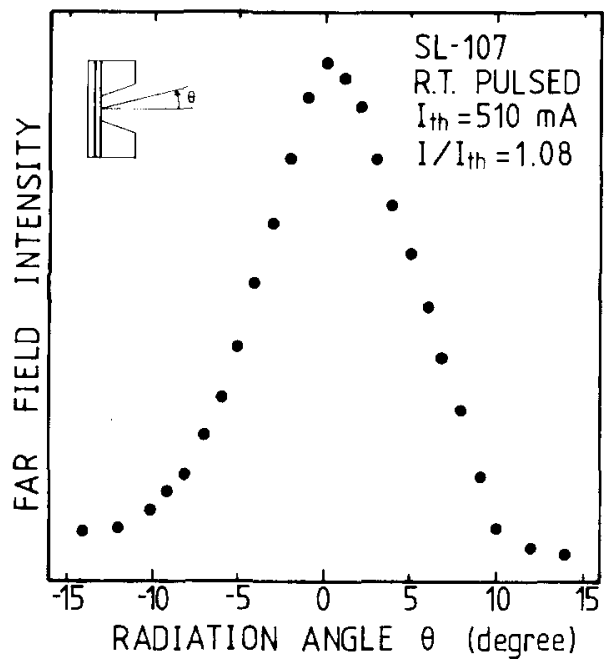

FIG 6. Far field pattern of the SE laser at room temperature.

curred three times and their mode spacing was about $110 \AA$, which corresponds to that associated with a cavity length = $7 \mu \mathrm{m}$. The mode spacing of the SE laser is much larger than conventional lasers $(5 \AA)$. The range of single mode operation was about $80 \mathrm{~K}$, and the lasing wavelength of one mode has a temperature dependence of $0.50 \AA / \mathrm{K}$. Therefore, the $\mathrm{SE}$ laser has a small wavelength shift and a wide temperature range of single mode operation comparable to, or rather better than, DFB lasers. The far field pattern of the SE laser at room temperature is shown in Fig. 6. The radiation angle was as sharp as $10^{\circ}$ (FWHM).

In conclusion, we obtained the GaAlAs/GaAs surface emitting injection laser with a round mesa of a $\mathrm{Zn}$-diffused $p^{+}$window/cap layer, and the first pulsed oscillation from $77 \mathrm{~K}$ to room temperature.

The authors wish to thank Professors Y. Suematsu, T. Tako, and S. Furukawa and Dr. K. Kishino of Tokyo Institute of Technology, and also Mr. T. Niina of Research Center of Sanyo Electric Co., Ltd. for encouragement and discussion of this work.

'K. Iga, H. Soda, T. Terakado, and S. Shimizu, Electron. Lett. 19, 457 (1983).

${ }^{2}$ I. Hayashi, M. B. Panish, and F. K. Reinhart, J. Appl. Phys. 42, 1929 (1971).

${ }^{3}$ E. Pinkas, B. I. MIller, I. Hayashi, and P. W. Foy, IEEE J. Quantum Electron. QE-9, 281 (1973).

${ }^{4}$ A. Ibaraki, S. Ishikawa, S. Ohkouchi, and K. Iga (unpublished).

\title{
Optical levitation using single mode fibers and its application to self- centering of microlenses
}

\author{
Jean-Paul Pocholle, Jean Raffy, Yves Combemale, and Michel Papuchon \\ Thomson-CSF, Laboratoire Central de Recherches, Domaine de Corbeville, B. P 10-91401 Orsay, France
}

G. Roosen and M. T. Plantegenest

Institut d'Optique Théorique et Appliquée, Bâtiment 503, Centre Universitaire d'Orsay, B. P43-91406 Orsay,

France

(Received 9 April 1984; accepted for publication 29 May 1984)

Optical levitation using single mode fibers has been experimentally demonstrated. The use of fibers in levitation experiments presents obvious advantages, in particular, concerning the case with which complicated optical paths can be realized without additional optical components. In addition the microsphere can be accurately deposited on the fiber end by simply controlling the optical guided power. This technique has been used to position microlenses self-centered on the guided mode to improve the coupling efficiency between a semiconductor laser and a single mode fiber.

Optical levitation of microspheres has been already reported and analyzed in the literature. ${ }^{1-3}$ We demonstrate in this letter the use of a single mode fibers in such experiments with the obvious advantage that complicated optical paths can be realized without additional optical components due to the flexibility of the optical fibers.

Moreover, we take advantage of one of the characteristics of optical levitation, that is, the equilibrium position of the microsphere is generally located on the axis of the laser beam. Consequently, when the levitation beam is emerging from an optical fiber the microsphere will be automatically centered on the beam mode. Thus, by controlling the guided power the microsphere can be deposited accurately self-centered on the guided mode at the end of the fiber. Hence, it forms a microlens which can be used to improve the coupling efficiency between semiconductor lasers and single mode fibers. ${ }^{4-7}$ Experimental results concerning the evolution of the coupled power with respect to the diameter of the sphere are given, and the method used to cement the lens on the fiber end is detailed.

In single mode fibers, the mode shape can be approximated by a Gaussian distribution ${ }^{8}$ characterized by the pa- 
rameter

$$
\omega_{0}=a_{e}\left(0.65+1.619 \mathrm{~V}_{e}^{-3 / 2}+2.879 \mathrm{~V}_{e}^{-6}\right),
$$

where $\omega_{0}$ is the mode spot size at $1 / e$ field amplitude, $a_{e}$ is the fiber equivalent core radius, and $V_{e}$ the equivalent normalized frequency taking into account the index profile perturbations. ${ }^{9}$ Using this radial dependence of the field distribution associated with the fundamental mode, we have been able to trap in stable optical potential well selected transparent solid glass spheres ranging from 10 to $30 \mu \mathrm{m}$ in diameter. This is achieved by adjusting the radiation pressure force of the beam issued from a vertically positioned single mode fiber (SMF). We have performed many optical levitation experiments with SMF designed either for argon $(\lambda=0.514$ $\mu \mathrm{m})$ or YAG lasers $(\lambda=1.064 \mu \mathrm{m})$. In such fibers the mode spot size and, consequently, the far field diffraction angle can be adjusted by modifying the source wavelength or the optogeometrical parameters of the fiber.

The microspheres were previously deposited on a glass substrate in the vicinity of the fiber end. The sphere is launched into the beam by breaking the strong forces of molecular attraction, known as the Van der Walls forces, by using mechanical vibrations applied to the support plate. With Gaussian mode distribution, the refractive spherical lens is self-centered in the divergent laser beam issued from the fiber due to the transverse components of the radiation pressure force. ${ }^{1,2}$ Depending on the optical power, the sphere is levitated at a distance $Z$ from the fiber end where the beam diameter $2 \omega(Z)$ is connected to $\omega_{0}$ and $Z$ by the well known formula

$$
\omega^{2}(Z)=\omega_{0}^{2}\left[1+\left(\lambda_{Z} / \pi \omega_{0}^{2}\right)^{2}\right] .
$$

The stability criterion is related to the ratio $\rho / \omega$ between the sphere and the beam radii and to the sphere refractive index value.

Figure 1 shows the stabilized sphere position versus the fiber output power. In this case, the fiber parameters were $\lambda_{c}$ $=1.21 \mu \mathrm{m}$ (cut-off wavelength) and $a_{e}=3.86 \mu \mathrm{m}$.

The monomode regime was achieved at the source wavelength $(\lambda=1.064 \mu \mathrm{m})$ by filtering the second mode using fiber bends, the fundamental mode spot size being equal

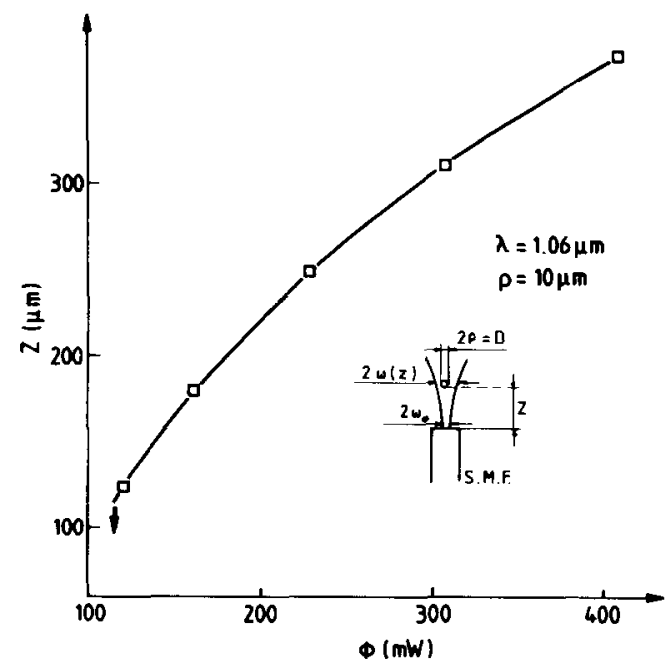

FIG. 1. Stable equilibrium position sphere vs the incident optical power (YAG laser $\lambda=1.06 \mu \mathrm{m}$ ) emerging from a single mode fiber.

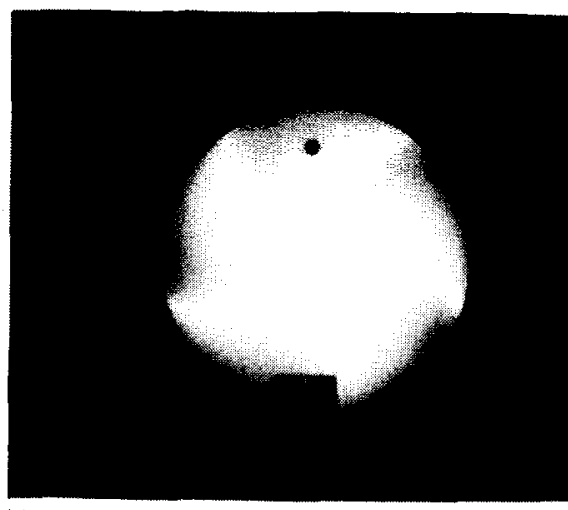

(a).

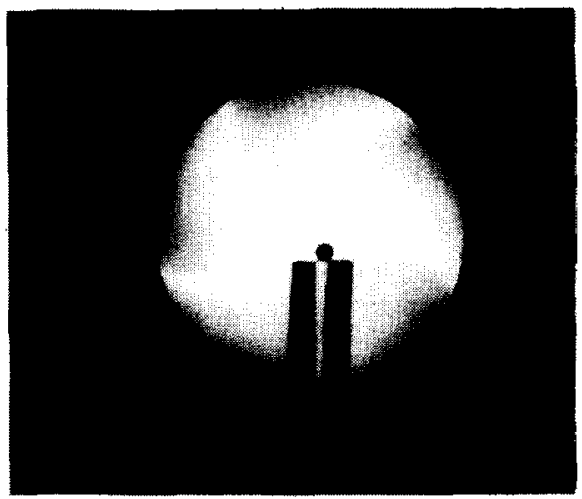

(b)

$$
D=30 \mu m
$$

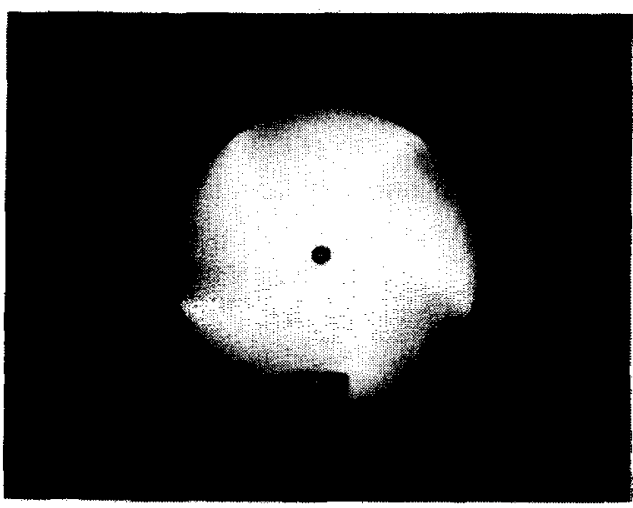

(c)

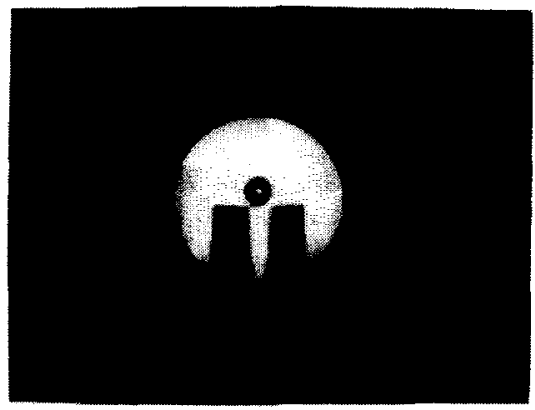

$$
D=45 \mu \mathrm{m}
$$

FIG. 2. Photographs of the sphere positions vs the sphere diameter and optical power: (a) $D=2 \rho=30 \mu \mathrm{m}, P=1 \mathrm{~W}$, (b) laser off, (c) $D=2 p=45$ $\mu \mathrm{m}, P=1 \mathrm{~W}$, (d) laser off. 


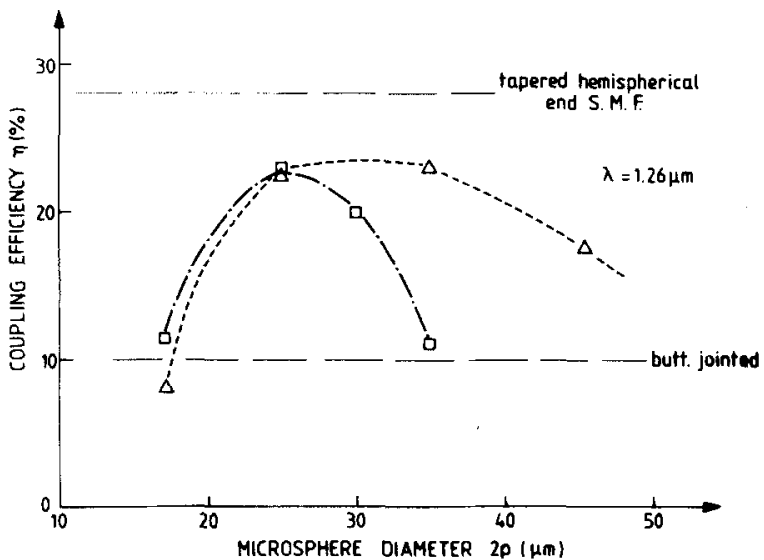

FIG. 3. Coupling efficiency against sphere lens diameter between SMF and laser diode; before (..-) and after $(\mathrm{O}-\mathrm{O})$ the curing phase.

to $\omega_{0}=3.9 \mu \mathrm{m}$. Figures 2(a) and 2(c) are photographs of the levitated microsphere positions for two different dielectric sphere diameters $(2 p=30$ and $45 \mu \mathrm{m})$. The incident flux is equal to $1 \mathrm{~W}$ corresponding to the $\mathrm{cw}$ YAG laser power emerging from the SMF. The radiation pressure exerted on the dielectric sphere is easily adjusted by modifying the optical flux issued from the fiber.

When the sphere is located in the $\rho / \omega(Z)>1$ regime, the microlens goes down to the fiber end. However, in this region, the transverse components always maintains the microlens centered on the mode shape. The centering of the microsphere was checked by analyzing the far field radiation pattern. Figures 2(b) and 2(d) show the fiber end with the positioned microlens. This procedure has been equally performed with SMF optimized for argon laser wavelength. The fiber parameters were $\omega_{0}=2.2 \mu \mathrm{m}$ and $\lambda_{c}=0.53 \mu \mathrm{m}$ in this case.

In YAG laser experiments, two stable equilibrium regions were observed. The first one depends on the ratio $\rho /$ $\omega(\boldsymbol{Z})$ between the sphere and beam radii. ${ }^{1,2,10} \mathrm{~A}$ second stable position was located in the vicinity of the modal near field.

To explain this it must be noted that the single mode fibers used were about $3 \mathrm{~m}$ long with a $\mathrm{GeO}_{2}$ doped $\mathrm{SiO}_{2}$ core and a slightly $\mathrm{F}$ doped cladding. They have been manufactured by the MCVD process, and have refractive index profile distortion such as dips around the fiber axis. For these fibers, the fundamental mode exhibits an annular intensity distribution at the source wavelength shorter than the $L P_{11}$ cut-off wavelength. ${ }^{11}$

This field configuration is equivalent to the $\mathrm{TEM}_{01}^{*}$ mode laser beam (donut mode) used in some levitation experiments. ${ }^{3,10}$

As demonstrated in Ref. 3, any radial displacement of the refractive sphere in this mode will result in a restoring force due to the optical potential well "optical bottle").

Consequently, the microlens remains self-centered whenever the transverse mode was encountered in our experiments.
To fix the microlens at the fiber end we proceed as follows: In the mounting procedure the end of the fiber is first properly cleared. Then a thin adhesive film is realized by dipping. When the desired microsphere lens is trapped in the optical potential well, the incident power is decreased to place the microlens onto the fiber end coated with the lowviscocity epoxy. The adhesive used (SANYU epoxy resin) is curable by combination of UV exposure and heating processes. Before the positioning of the microsphere onto the fiber end, the resin is exposed to UV rays for $1 \mathrm{~min}$ for prepolymerization. In a second step, with the sphere centered on the fiber end, 4 min of UV exposure time is performed. The curing time at $60^{\circ} \mathrm{C}$ for a strong adhesive bond is $14 \mathrm{~h}$.

The coupling efficiency results are presented in Fig. 3. The two curves show the coupling efficiency between laser diode and SMF versus the sphere radius.

The dashed and dot-dashed curves correspond to the coupling efficiency before and after the heating cementation process, respectively. The SMF parameters were $\lambda_{c}=1.18$ $\mu \mathrm{m}, \omega_{0}(\lambda=1.064 \mu \mathrm{m})=3.6 \mu \mathrm{m}$. The InGaAsP laser diode used in the experiments emits at $\lambda=1.26 \mu \mathrm{m}$ and was characterized by an asymmetry in the laser emission pattern (FWHM beam angle parallel and perpendicular to the laser junction plane $\theta_{\|}=20^{\circ}, \theta_{\perp}=50^{\circ}$ ).

For comparison, coupling efficiency measurements for butt joint and tapered hemispherical lens end SMF techniques are shown in Fig. 3.

In conclusion, optical levitation using SMF has been experimentally demonstrated and applied to the self centering of microlenses to improve the coupling efficiency between SMF and semiconductor lasers.

It is to be noted that the optical power levels used for the levitation process are not too large and are consistent with the high output power delivered by the phase-locked injection laser arrays. ${ }^{12}$

The authors would like to acknowledge J. M. Sandoz for providing the epoxy resin, the Fibres Optiques and Semiconducteurs pour l'Optoélectronique Laboratories of Thomson-CSF for the realization of the SMF and laser diodes used in their experiments.

${ }^{1}$ A. Ashkin and J. M. Dziedzic, Appl. Phys. Lett. 10, 283 (1971).

${ }^{2}$ G. Roosen and C. Imbert, Phys. Lett. 591, 6 (1976).

${ }^{3}$ G. Roosen and C. Imbert, Opt. Commun. 26, 423 (1978).

${ }^{4}$ J.I. Yamada, Y. Murakami, J. I. Sakai, and T. Kumura, IEEE J. Quantum Electron. 16, 1067 (1980).

${ }^{5}$ H. Kuwahara, M. Sasaki, and N. Tokoyo, Appl. Opt. 19, 2578 (1980).

${ }^{6}$ P. Kayoun, C. Puech, M. Papuchon, and H. J. Arditty, Electron. Lett. 17, 400 (1981).

${ }^{7}$ G. Eisenstein and D. Vitello, Appl. Opt. 21, 3470 (1982).

${ }^{8}$ D. Marcuse, Bell Syst. Tech. J. 56, 703 (1977).

${ }^{9}$ H. Matsumara and T. Suganuma, Appl. Opt. 19, 3151 (1980).

10A. Ashkin and J. M. Dziedzic, Appl. Phys. Lett. 24, 586 (1974).

"W. A. Gambling, H. Matsumura, and C. M. Ragdale, Opt. Quantum Electron. 10, 301 (1978).

${ }^{12}$ D. R. Scifes, R. D. Burnham, c. Lindström, W. Streifer, and T. L. Paoli, Appl. Phys. Lett. 42, 645 (1983). 